\title{
AVATARES DEL DERECHO MODERNO. HACIA UN NUEVO CONCEPTO DE NORMA
}

\author{
Avatarts of modern law. Towards a new concept of norm \\ Danilo Billiard Bravo \\ Universidad de Chile, Santiago, Chile. \\ dbilliard@gmail.com
}

\section{Resumen}

Cuando la reivindicación y/o recuperación de los derechos sociales aparece como el eje más pregnante de un debate político enmarcado en las tensiones y consecuencias derivadas del derrotero neoliberal, se hace preciso interrogar el paradigma jurídico -dispositivo orientado a la separación entre nomos y bíos y, en efecto, a la subordinación de la vida al derecho- desde la problematización del concepto de norma que la modernidad ha suministrado, con el propósito de desafiar sus límites epistémicos para habilitar un punto de intersección donde vida y derecho se imbriquen a partir de lo que Spinoza denominara como "inmanencia recíproca", contribuyendo de esta forma al pensamiento de una biopolítica afirmativa.

Palabras clave: Derecho, biopolítica, vida, norma, comunidad.

\begin{abstract}
When the claim and / or recovery of social rights appears as the most pregnant axis of a political debate framed in the tensions and consequences derived from the neoliberal course, it is necessary to interrogate the legal paradigm -dispositive oriented to the separation between nomos and bios and, in effect, to the subordination of life to law- from the problematization of the concept of norm that modernity has provided, with the purpose of challenging its epistemic limits to enable a point of intersection where life and law are imbricated from what that Spinoza denominated like "reciprocal immanence", contributing in thos way to the thought of an affirmative biopolitics.
\end{abstract}

Keywords: Law, biopolitics, life, norm, community.

Fecha de Recepción: 15/01/2019 - Fecha de Aceptación: 22/07/2019 
No le demandes a la política que restituya los 'derechos' del individuo, tal como los ha definido la filosofía. El individuo es producto del poder. Lo que hace falta es "des-individualizar" por medio de la multiplicación y el desplazamiento, combinaciones diversas. El grupo no debe ser un lazo orgánico que unos individuos jerarquizados, sino un constante generador de des-individualización,

Michel Foucault

\section{Introducción}

En un contemporáneo debate político acerca de la democracia y el rol del Estado, decir "derecho" parece no concitar demasiadas observaciones o, cuando menos, inquietudes que conduzcan a unas advertencias destinadas a tomar precaución y cierta distancia de los entusiasmos en torno a la recuperación de los derechos sociales, defenestrados por la mercantilización de los servicios públicos a causa del derrotero neoliberal.

Pero ¿qué significación guarda la demanda de esos "derechos sociales" azuzados por un malestar creciente? Lo que a partir de allí pareciera proyectarse es un modo histórico de la seguridad social, como si lo que estuviera en juego es un retroceso en el tiempo para resarcir los anacrónicos tejidos de una soberanía estatal ensamblada a la garantía de los derechos individuales, que hace además imposible situarlos en oposición a la misma.

Si el umbral biopolítico (es decir, la conservación y protección de la vida ante el riesgo de muerte, como asunto primordial del poder) marca un punto de no retorno respecto al marco analítico y al léxico que garantizó el orden moderno y con ello al propio pensamiento jurídico, la única respuesta posible es una revisión deconstructiva de sus categorías para dar cabida a otros horizontes de sentido, en la medida que los modelos conceptuales que todavía prevalecen para buscar una salida ante los problemas del mundo contemporáneo, siguen atados a una matriz hobbesiana con su correspondiente lógica sacrificial, en que la vida queda supeditada, a cambio de su protección, a la decisión trascendente que la anticipa y la retiene.

De hecho, el que hoy la seguridad pública sea un eje prioritario para los gobiernos $^{1}$, es un signo de cómo en la biopolítica contemporánea (de tipo inmunitaria) las viejas distinciones entre guerra y paz, o entre vida y muerte, y aún

\footnotetext{
1 "La seguridad es el más alto concepto social de la sociedad burguesa, el concepto de la policía, que toda la sociedad existe sólo para garantizar a cada uno de sus miembros la conservación de su persona, de sus derechos y de su propiedad. Es en este sentido que Hegel llama a la sociedad burguesa «el Estado de necesidad y de entendimiento». Por el concepto de la seguridad la sociedad burguesa no se eleva sobre su egoísmo. La seguridad es, más bien, el aseguramiento del egoísmo" (Marx 2009 149-150).
} 
más, entre excepción y derecho, han quedado obsoletas, no tanto porque una se vuelque sobre y contra la otra, sino porque terminan coincidiendo plenamente. Así, ya no es forzoso ni exagerado sostener que la ley y la fuerza son una misma cosa: la fuerza soberana de donde emana la ley es el contenido que la funda y que, por obligación, está llamada a legitimar.

Por eso es que conceptualmente, el derecho goza de un enorme prestigio que ha estado lejos de agotarse. Si bien podrían exigírsenos algunas precisiones técnicas -relativas al lenguaje jurídico- al momento de formular una interrogación al derecho moderno, el propósito que este ensayo persigue es abordar críticamente la legitimidad que le proporciona su asimilación semántica, si es que consideramos, como Esposito, que "la tarea de la reflexión filosófica es el desmontaje crítico de las opiniones corrientes, o sea, la interrogación radical de lo que se presenta como inmediatamente evidente" (2011 55).

Nada más inmediatamente evidente que la noción de Derecho, cuya hegemonía radica no tanto en la voluntad de someterse a su condición prescriptiva, sino más bien en el enraizamiento cultural que lo vuelve un verosímil. Es en ese sentido que la doctrina de la soberanía de Carl Schmitt formulada en su célebre Teología Política, nos permite aproximarnos a la que quizá sea la ambivalencia constitutiva del derecho moderno: la inclusión de la excepción al interior de la norma. Precisamente, porque Schmitt define la excepción al derecho (el Estado de excepción) como el mecanismo para garantizar su continuidad, a cuya salvaguarda se encuentra la soberanía en su decisión última respecto a las amenazas que desafían al orden jurídico.

En esa dirección apunta Giorgio Agamben cuando interpreta el texto schmittiano aludido como una respuesta al ensayo Para una crítica de la violencia de Walter Benjamin, cuya finalidad era posibilitar un "más allá del derecho" o una zona de anomía, es decir un poder, violencia o unas relaciones de fuerza (todos términos que la palabra alemana Gewalt puede englobar) sustraídas de cualquier inscripción jurídica ${ }^{2}$, aspecto consustancial a un concepto de soberanía incapaz de decidir en última instancia sobre los problemas jurídicos (el soberano barroco), de donde emerge una violencia revolucionaria que no funda ni conserva derecho -a decir verdad, un poder destituyente-, dando paso a un nuevo tiempo histórico.

¿Cuál puede ser el sentido de un derecho que sobrevive de semejante modo a su deposición? La dificultad con la que se enfrenta Benjamin corresponde a un problema que se puede formular $-\mathrm{y}$ de hecho fue formulado por primera vez por

\footnotetext{
2 "No puede haber, según Schmitt, una violencia pura, esto es absolutamente fuera del derecho, porque en el estado de excepción ella está incluida en el derecho a través de su misma exclusión. El estado de excepción es, entonces, el dispositivo a través del cual Schmitt responde a la afirmación benjaminiana de una acción humana integralmente anómica" (Agamben 2005 106).
} 
el cristianismo primitivo y luego por la tradición marxista- en los siguientes términos: ¿qué pasa con la ley después de su cumplimiento mesiánico? (Es la controversia que enfrenta a Pablo con los judíos de su tiempo.) ¿Y qué pasa con el derecho en la sociedad sin clases? (Es exactamente el debate que tiene lugar entre Vysinskij y Pasukanis). A estas preguntas intenta responder Benjamin con su lectura del "nuevo abogado". No se trata, obviamente, de una fase de transición, que no llega nunca al final que debería conducir, ni mucho menos de un proceso de infinita deconstrucción que, manteniendo el derecho en una vida espectral, ya no es capaz de concluirlo. Lo decisivo aquí es que el derecho -ya no practicado sino estudiado- no es la justicia, sino solamente la puerta que conduce hacia ella. Abrir un paso hacia la justicia no es la cancelación sino la desactivación y la inoperancia del derecho, es decir un uso diferente del mismo (Agamben 120).

La operación benjaminiana es audaz e incisiva: se trata de que al derecho le es destituido su carácter normativo y deviene inaplicable, para transformarlo en un objeto de reflexión. Si la práctica del derecho (sea público o privado) consiste en la repartición de bienes apropiables ${ }^{3}$, la inaplicabilidad lo dota de un uso distinto, ya que -en los términos de Simone Weil- por universal que se pretenda, el derecho ha sido siempre relativo a las cosas personales ${ }^{4}$, a lo que es propio de alguien y no impropio de todos porque, en caso que así fuera (como lo precisa Esposito) se trataría simplemente de un hecho que no requiere ser calificado jurídicamente, de donde se sigue además que el Derecho se despliega como un mecanismo de inclusión excluyente.

Puesto que la vida ha sido el objeto del derecho moderno (esa modernidad biopolítica donde el poder toma la vida a su cargo), lo que queda es pensar un derecho que apueste a superar los remanentes metafísicos de la filosofía política moderna, para abrirle paso a un derecho que sea equivalente a la vida (preguntándonos tangencialmente ¿qué es una vida?), hasta que cada vida en su especificidad, diferencia o condición, sea a la vez un derecho, para lo cual es imprescindible aproximarse a un nuevo concepto de norma.

\footnotetext{
3 "La forma jurídica asegura a la comunidad del riesgo de conflicto mediante la norma fundamental de la absoluta disponibilidad de las cosas para ser usadas, consumidas o destruidas por quien pueda reivindicar legítimamente su posesión sin que nadie más pueda interferir. Pero de este modo invierte el vínculo afirmativo de la obligación común en el derecho puramente negativo de todo individuo a excluir a cualquier otro de la utilización de lo que le es propio. Esto quiere decir que la sociedad jurídicamente regulada es unificada por el principio de común separación: sólo es común la reivindicación de lo individual, así como la salvaguarda de lo que es privado constituye el objeto del derecho público" (Esposito 2009 40-41).

${ }^{4}$ Para una aproximación al debate sobre la categoría de Persona y su vinculación al Derecho, se recomienda el ensayo de Roberto Esposito “El Dispositivo de la Persona” (2011).
} 


\section{Auge de la biopolítica y crisis del paradigma jurídico moderno.}

Las críticas de Walter Benjamin al derecho en su ensayo dedicado al problema de la violencia mítico-jurídica, constituyen una pieza teórica de gran valor que ha sido relevante para las formulaciones contemporáneas que tanto Giorgio Agamben como Roberto Esposito -ambos filósofos italianos y derivas foucaultianas- han introducido al debate actual sobre la biopolítica. Se podría decir, sin exagerar, que el valor del ensayo alcanza un nivel superlativo, transformándose en el estímulo a partir del cual se han articulado interpretaciones diversas y novedosas que profundizan esa línea de análisis ${ }^{5}$.

Tanto en Agamben como en Esposito, se puede afirmar que derecho y violencia permanecen atados en una relación que resulta constitutiva para ambos términos. Sin embargo, la relevancia de los enfoques que aquí queremos destacar pasa por la resignificación que los autores hacen del derecho, situándolo (para el caso de Esposito) en plena coincidencia con la vida a partir de la filosofía de Baruch Spinoza pero también del pensamiento de George Canguilhem y Gilles Deleuze. Respecto a Agamben, podemos sugerir que el último trayecto del capítulo dedicado a las aproximaciones y desavenencias entre Carl Schmitt y Walter Benjamin ("Gigantomaquia en torno a un vacío") -donde el derecho no sólo resulta inaplicable sino que aparece como un motivo de juego- es una contribución que complementa la noción de biopolítica afirmativa introducida paralelamente por Esposito.

\subsection{Biopolítica}

Cuando Michel Foucault introduce al debate histórico y filosófico el neologismo biopolítica, es decir esa política donde la vida biológica está implicada en los cálculos estratégicos del poder, no sólo está desplazando los presupuestos categoriales antropocéntricos y/o humanistas que definían la vida a partir de concepciones trascendentales como las de hombre, sujeto o conciencia ${ }^{6}$, sino que además va a preguntarse respecto a la aporía que parece resultar inherente a la misma: ¿cómo una política de vida puede llegar a convertirse en amenaza de muerte? La respuesta ante esa interrogante ha sido desarrollada por Roberto Esposito mediante la oposición contrastiva que existiría entre los términos

\footnotetext{
${ }^{5}$ Piénsese también en las conferencias de Jacques Derrida (1989-1990) sobre el derecho, un abordaje tanto singular como significativo respecto a la consustancialidad entre fuerza y ley.

${ }^{6}$ Situado en un plano semántico que lo hace coincidir con las elaboraciones de Heidegger respecto a la "vida fáctica" (Dasein).
} 
inmunidad y comunidad, proponiéndola como paradigma explicativo de todo el proyecto moderno.

En efecto, si el significado de la comunidad proveniente del latín communitas, y más precisamente de la raíz cum-munus, que se traduce como don, regalo o reciprocidad, la inmunidad (más bien, immunitas) es la sustracción o dispensa de aquello que para el resto constituye una obligación común: el munus. Así, transformándose en la condición negativa de la comunidad (immunitas es lo que priva del munus), la inmunizará estratégicamente para resguardarla de la amenaza que implica la disolución de los límites identitarios que comporta la comunidad (al disolver la diferencia de lo propio que es de Uno, con lo común de todos), cuya función ha sido desempeñada principalmente por el Derecho.

A aquello -a ese inaceptable munus- intenta responder la filosofía política moderna. ¿Cómo? Aquí reaparece la categoría de "inmunización" que, como hemos visto, constituye el más incisivo contrapunto semántico de la communitas. Al respecto quisiera proponer la tesis de que esa categoría adquiere tanta relevancia que se le puede tomar como clave explicativa de todo el paradigma moderno, tanto o más que otros modelos hermenéuticos, como los expresados en los términos "secularización”, "legitimación”, "racionalización”, lo cuales opacan, o atenúan, su pregnancia léxica. Y esto porque resuena en ellos la separación con respecto al pasado premoderno, pero no la inversión de perspectiva y la potencia de negación que contrapone directamente immunitas a communitas. El "inmune" no es simplemente distinto del "común"; es su contrario, que lo vacía hasta la extinción completa no sólo de sus efectos, sino de su presupuesto mismo (Esposito 2012 3940).

El nexo negativo entre nomos y bíos, o entre política y vida, habría encontrado en la experiencia del nazismo su punto de apogeo. Y esto -como es explicado por Esposito- porque el papel desempeñado por el derecho en la biocracia nazi resultaba funcional a su deriva tanatológica expresada en la cruenta política de exterminio de las "razas inferiores"7. Si bien la primacía del saber médico y antropológico en esta biopolítica negativa resulta decisiva e incuestionable, de igual forma el derecho actuaba desde su función inmunitaria, en la medida que si su objetivo es la conservación de la vida, lo hará concibiendo a la muerte como el instrumento de conservación de la misma.

\footnotetext{
${ }^{7}$ Importante es atender a la diferencia que el nazismo sostenía entre vida y existencia, haciendo de la mera existencia la elevación de la muerte al rango de la auténtica vida, transformándose en su principal amenaza biológica: una existencia prometida a la muerte que los mecanismos de biopoder debían empujar hacia su deceso definitivo a través del despliegue de técnicas inmunitarias (supresión anticipada del nacimiento, por ejemplo), haciendo de ello el modo de conservación de la vida del pueblo alemán.
} 
Ya hemos visto que el objetivo declarado del derecho es la conservación de la vida. Y también que la vida puede ser conservada sólo si se le aferra en el pliegue de una inexorable anticipación que la prejuzga culpable aun antes de que cada uno de sus actos pueda ser juzgado. Esto significa que tal conservación no es indolora. Es más, que requiere una condena preventiva de aquello que se quiere salvar. A tal condena remite la reducción de la vida a pura materia: su sustracción a toda forma de vida justa o común (Esposito 2005 51).

Prueba de ello es que, pese a que Carl Schmitt consideró que Alemania atravesaba el umbral de una dictadura soberana, la constitución de Weimar nunca fue disuelta definitivamente, de modo que su permanencia no resultaba un impedimento para que se desplegara el racismo homicida del hitlerismo, en la medida que el carácter inmunitario del derecho lo ponía en estrecho contacto con la vida biológica. De lo que se trata es del ensamblaje entre derecho y biología: biologización del derecho y juridización de la vida.

Sólo de una decisión jurídica podía surgir la subdivisión del bíos humano en zonas de diferente valor. Justamente de esta continua confusión entre causa y consecuencia, motivación y resultado, obtuvo la máquina biopolítica del nazismo su más poderoso efecto mortífero. Para que la vida pudiera constituir la referencia objetiva, concreta, facticia, del derecho, debía estar previamente normativizada con arreglo a precisas cesuras jurídico-políticas. De ello resulta un sistema de doble determinación cruzada. Como surge también de la competencia combinada entre el poder de los médicos y el de los jueces en la aplicación de las leyes biopolíticas (esto es, tanatopolíticas), en el nazismo, biología y derecho, vida y norma, se aferran mutuamente en una doble presuposición encadenada: la norma presupone el carácter fáctico de la vida como su contenido principal, y, a su vez, la vida presupone la cesura de la norma como su definición preventiva (Esposito 2011 294).

En este pasaje, Esposito también se remite al carácter personalista del Derecho, como lo sugieren las críticas de Simone Weil's:

A esta dinámica expropiatoria -en la cual la comunidad reconoce el sentido profundo de su propio munus- es que responde en contraste la inmunización jurídica. Esta reconstituye el pasaje directo entre derecho y sujeto interrumpido por la línea divisoria de la obligación. Ya no "dado que yo tengo obligaciones, los otros tendrán derechos"; sino: "dado que yo tengo derechos, los otros tendrán obligaciones". Dicho pasaje se produce a través de la idea de "persona jurídica". Si la communitas necesariamente remite a algo "impersonal" -o aun, "anónimo", como precisa Weil-, el

\footnotetext{
8 "Carece de sentido decir que los hombres tienen, por un lado, derechos, y por otro, deberes. Esas palabras sólo expresan puntos de vista diferentes. Su relación es la del objeto y el sujeto. En sí mismo, un hombre sólo tiene deberes, entre los que se cuentan algunos para consigo mismos; los demás, desde su punto de vista, sólo tienen derechos" (Weil 1996 23).
} 
principio inmunitario del derecho vuelve a ubicar en el centro de la escena a la persona como única titular de derechos (2005 38).

En efecto, si su lógica de funcionamiento es la de un mecanismo de inclusión excluyente, es porque desde su génesis la forma jurídica se rige por la semántica de la pertenencia (proprium). Un derecho siempre será de alguien en particular, puesto que en caso contrario -es decir que fuera de todos- se trataría simplemente de un hecho que no requiere de una denominación jurídica9 ${ }^{9}$ Ergo, la generalización del derecho supone la extensión de su tonalidad mercantil, asegurando a la comunidad del riesgo de conflicto "mediante la norma fundamental de la absoluta disponibilidad de las cosas para ser usadas, consumidas o destruidas por quien pueda reivindicar legítimamente su posesión sin que nadie más pueda interferir" (Esposito 2005 40).

Se esclarece entonces la conexión entre inmunización jurídica, apropiación y violencia, sintetizada en la noción de soberanía, definida a su vez como el fundamento antinómico del derecho. Puesto que derecho y violencia conforman una alianza recíproca en que uno actúa como la justificación o presupuesto del otro, se constituye allí un vínculo de mutua dependencia, y para que la vida sea inmunizada jurídicamente el derecho deberá condenar la vida a la culpa perpetua ¿Cómo? Haciendo de la culpa el motivo de la condena. La vida es culpable de la muerte en razón de la cual ha podido seguir existiendo, como el mito de Níobe narrado por Walter Benjamin.

Es aquí donde también va a erguirse el núcleo mítico del derecho ${ }^{10}$, que se pone de manifiesto en la figura de la excepción reivindicada por Schmitt ${ }^{11}$. Sólo internalizando aquello que le es externo, y proporcionándolo en dosis soportables, el derecho puede inmunizar la potencia del devenir y contener el impulso natural de la vida a sobrepasarse, porque "sólo el constante retorno del pasado puede asegurar al presente contra la incertidumbre que el futuro hace pesar sobre él" (Esposito 2005 49)

\footnotetext{
9 "Porque el derecho, en su función inmunizadora - de la comunidad y desde la comunidad- tiene la imagen exacta del proprium. Y poco importa si se trata de derecho privado o derecho público: en todos los casos es propio, en el sentido de que 'pertenece' al sujeto, público o privado, que se declara portador de él" (Esposito 2005 39)

${ }^{10}$ En su crítica a las prácticas judiciales de la modernidad, Foucault recusa la idea de un saber esencial y la preeminencia de un sujeto de conocimiento que le es inherente, de modo que el derecho no será sino el resultado de un conjunto de prácticas sociales (de control y vigilancia) devenidas luego en normas jurídicas.

${ }^{11}$ Carl Schmitt definía el estado de excepción como la suspensión temporaria del ordenamiento jurídico para garantizar su vigencia.
} 
Así, retenida al interior de sus confines biológicos, la vida puede ser protegida por el derecho a través de su relación con la muerte, produciendo la copertenencia entre sacrificio y conservación, actuando de modo preventivo frente a todo acontecimiento potencial (futuro) que pueda rebasar su dominio.

Esta posibilidad formal es la que precisamente se sacrifica a la reproducción de su estrato biológico, a la perpetuación de la simple superviviencia. Benjamin refiere este mecanismo sacrificial a la distinción entre ámbito de la "vida desnuda" y ámbito de lo "viviente", esto es, de aquel que se separa de la objetividad de la vida para hacerse sujeto de ella. Sobre este último se descarga la violencia del aparato jurídico: de hecho, su mecanismo inmunitario consiste en perpetuar la vida mediante el sacrificio de lo viviente (Esposito 2005 51).

\subsection{Excepción}

No es desconocido que para los jerarcas del Tercer Reich, Alemania estaba afectada por una grave enfermedad, donde la vida de ese pueblo podía ser garantizada únicamente empujando hacia la muerte a quienes eran considerados una amenaza biológica para su existencia ${ }^{12}$. En esa convicción de orden científico, el lenguaje jurídico pudo adaptarse sin dificultades a los preceptos de esta biopolítica tanatológica, para que el derecho (ese bioderecho) se desenvolviera precisamente por la vía de la excepción.

Una "fuerza-de-ley" semejante, en la cual la potencia y el acto son separados radicalmente, es ciertamente algo así como un elemento místico o, sobre todo, una fictio a través de la cual el derecho busca anexarse la propia anomia. Pero cómo es posible pensar tal elemento "místico" y de qué modo actúa en el estado de excepción es exactamente el problema que es preciso intentar aclarar (Agamben 2005 81).

Una interpretación biopolítica del paradigma jurídico moderno no entrega señales respecto a que la excepción se imponga ante la ley, sino que nos exhibe cómo la crisis de la modernidad gatillada por el nazismo, consiste fundamentalmente en la emergencia de una ley de excepción, que sin embargo concierne a la constitución misma del dispositivo jurídico. En la biopolítica contemporánea, la excepción será entonces la forma que adquirirá la ley, y es por eso que Agamben es precavido al distinguir entre los decretos constitucionales de emergencia, y la excepción devenida en modelo de funcionamiento del derecho. El estado de excepción en el cual se encontraba Alemania bajo la presidencia de Hindenburg fue justificado por Schmitt en el plano constitucional a través de la

\footnotetext{
12 En los juicios de Núremberg, los médicos del nazismo no creían haber traicionado el juramente hipocrático, al considerar que sus actividades se inscribían dentro de un marco terapéutico: extirpar el cáncer que afectaba la salud del pueblo alemán.
} 
idea de que el presidente actuaba como "custodio de la constitución" (Schmitt, 1931); pero el fin de la República de Weimar muestra por el contrario con claridad que una "democracia protegida" no es una democracia, y que el paradigma de la dictadura constitucional funciona sobre todo como una fase de transición que conduce fatalmente a la instauración de un régimen totalitario (Agamben 2005 46). Y esto, porque el artículo 48 de la constitución de Weimar (a propósito de su relación con el ascenso de Hitler) se generaliza al punto de transformarse en un paradigma biopolítico de gobierno, cuyo motivo es la defensa de la vida de un pueblo ante una amenaza real o potencial, ya que "el derecho soberano, en el régimen biopolítico, no es tanto la facultad de dar muerte como de eliminar por anticipado la vida" (Esposito 2011 234).

Desde luego que esto nos lleva a las formulaciones críticas de Michel Foucault respecto a la identificación del poder con la concepción jurídica: ley restrictiva de tipo soberana que prohíbe $^{13}$. En efecto, y aunque Foucault no se interesó en el análisis del derecho (por recusar las categorías universales), los nuevos mecanismos de poder aparecen más bien asociados con los procesos de normalización -en el marco de la creciente influencia del saber médico y biológico en occidente-, de modo que la soberanía se traduce como una fuerza de ley.

Si en la analítica del poder de Foucault, lo que está en juego no es la represión sino la producción de verdad, la normativización absoluta de la vida que Esposito define como uno de los dispositivos inmunitarios del nazismo- hará del derecho una proyección de las cesuras biológicas que la contienen y determinan (sobre la base de la teoría de la degeneración y del evolucionismo darwiniano). Así, quedará la vida en manos del derecho, que la sojuzgará a partir de preceptos de orden científico que lo autorizan. Es así cómo en esta forma histórica del poder, el derecho hará cumplir el mandato soberano de decidir sobre la vida y la muerte.

El racismo está pues ligado con el funcionamiento de un Estado que está obligado a valerse de la raza, de la eliminación de las razas o de la purificación de la raza para ejercer su poder soberano. El funcionamiento, a través del biopoder, del viejo poder soberano del derecho de muerte, implica el funcionamiento, la instauración y la activación del racismo. Y creo que éste radica efectivamente aquí (Foucault 1996 209).

13 “Creo que podemos analizar la razón de ello en los siguientes términos: en el fondo, en Occidente, los grandes sistemas establecidos desde la edad media, se desarrollaron por intermedio del crecimiento del poder monárquico a costas del poder o mejor de los poderes feudales. Ahora en esta lucha entre los poderes feudales y el poder monárquico, el derecho fue siempre el instrumento del poder monárquico contra las instituciones, las costumbres, los reglamentos, las formas de ligación y de pertenencia características de la sociedad feudal" (Foucault 2014 53). 
Por eso no es válido argumentar que en la experiencia nazi el derecho fuera depuesto, porque más bien el ámbito de la ley, al anexarse la anomía, hizo del uso de la fuerza y de la decisión arbitraria los componentes de un procedimiento judicial. De ahí que el tiempo del poder soberano no sea superado por el auge de la biopolítica sino que es retenido al interior de sus confines para ejercerlo de un modo inverso: ya no como producción de la ley sino como activación excepcional de la misma. Es en ese sentido que Agamben sostiene que el Estado de excepción no es ni externo ni interno al ordenamiento jurídico:

Y el problema de su definición concierne precisamente a un umbral, o a una zona de indiferenciación, en el cual dentro y fuera no se excluyen sino que se indeterminan. La suspensión de la norma no significa su abolición, y la zona de anomia que ella instaura no está (o al menos pretende no estar) totalmente escindida del orden jurídico. De aquí el interés de aquellas teorías que, como la de Schmitt, complican la oposición topográfica en una más compleja relación topológica, en donde está en cuestión el límite mismo del ordenamiento jurídico. En todo caso, la comprensión del problema del estado de excepción presupone una correcta determinación de su localización (o ilocalización). Como veremos, el conflicto sobre el estado de excepción se presenta esencialmente como una disputa sobre el locus que le compete" (Agamben 2005 59-60).

De este modo, la ley ya no es la decisión trascendente impuesta desde arriba, sino que emana de la inmanencia de la vida sujeta a una herencia de sangre, que hace de la biología el fundamento primigenio y último de la existencia, en que el cuerpo es suturado para hacerlo coincidir plenamente con un código espiritual biologizado -de donde surge la noción de raza- rompiendo así con cualquier lógica dualista (inscrita en la tradición cristiana y luego cartesiana) sin por ello negar la dimensión subjetiva y abstracta de la vida, la que sin embargo se alberga en su fondo somático. Como es precisado por Esposito, en esos motivos la teoría de la transmisión del plasma germinativo y la herencia psicomática (derivada de éste) fueron decisivas, y no es extraño que en su desarrollo inicial hayan estado influidas por el dogma de la predestinación de raigambre calvinista.

Pero no es el decisionismo soberano de Schmitt lo que determinará el repertorio de la categoría de excepción en la norma biopolítica del nazismo. No se trata tanto de la suspensión del derecho como de su codificación en clave objetivamente somática: fuera de cualquier mediación institucional, la vida biológica se volvía su referente inmediato. Es decir, la excepción se constituye a partir de la conformación biológica del organismo corpóreo de un pueblo, sujeto a las leyes de la herencia que lo han posibilitado, ubicándose la vida en zonas de distinto valor y quedando capturada en la absoluta normativización, para 
determinar su destino por medio del contenido étnico que la envuelve desde su origen, apelando a un derecho natural relativo a la "naturaleza humana" 14 .

En ese intersticio se ubican las aproximaciones y desavenencias entre Schmitt y Benjamin. Cuando este último hace coincidir el estado de excepción con la regla, no es equiparable al Estado de excepción de Schmitt, definido como el ámbito "exterior del interior" del ordenamiento jurídico (el afuera del adentro). En cambio, si la violencia pura en Benjamin al estar sustraída del universo míticojurídico de la soberanía, no asume la forma de un poder constituyente; empero, el que no funde ni conserve derecho no debe ser confundido con una postura ácrata, sino más bien como una discontinuidad histórica que modifica su uso canónico y trascendente.

Al desenmascaramiento de la violencia mítico-jurídica que opera la violencia pura corresponde en el ensayo sobre Kafka, como una suerte de resto, la enigmática imagen de un derecho que ya no se practica sino que sólo se estudia. Hay todavía, por lo tanto, una figura posible del derecho después de abandonar su nexo con la violencia y el poder; pero se trata de un derecho que ya no tiene fuerza ni aplicación, como aquel en cuyo estudio se sumerge el "nuevo abogado" hojeando "nuestros viejos códigos"; o como aquel que tal vez podía tener en mente Foucault cuando hablaba de un "nuevo derecho" librado de toda disciplina y de toda relación con la soberanía" (Agamben 119-120).

\section{Derecho y vida: acerca de una biopolítica afirmativa.}

Puesto que, al decir de Nietzsche ${ }^{15}$, el conocimiento no es una extensión de la naturaleza ni la naturaleza está provista de leyes inmanentes que determinen su objetiva interpretación a través de normas jurídico-políticas ¿de qué forma el derecho podría resultar coincidente con la vida sin a su vez negarla? Únicamente cuando la vida deja de estar aprisionada en una norma fundamental que la modeliza, para hacer de la norma el equivalente de la vida en tanto que potencia.

\footnotetext{
14 "Los filósofos conciben los afectos, cuyos conflictos soportamos, como vicios en los que caen los hombres por su culpa. Por eso suelen reírse o quejarse de ellos, criticarlos o (quienes quieren aparecer más santos) detestarlos. Y así, creen hacer una obra divina y alcanzar la cumbre de la sabiduría, cuando han aprendido a alabar, de diversas formas, una naturaleza humana que no existe en parte alguna y a vituperar con sus dichos la que realmente existe" (Spinoza 2013 97-98).

15 "Nietzsche quiere decir que no hay naturaleza, ni esencia ni condiciones universales para el conocimiento, sino que éste es cada vez el resultado histórico y puntual de condiciones que no son del orden del conocimiento. El conocimiento es un efecto o un acontecimiento que puede ser colocado bajo el signo del conocer, no es una facultad y tampoco una estructura universal. Aun cuando utiliza ciertos elementos que pueden pasar por universales este conocimiento será apenas del orden del resultado, del acontecimiento, del efecto" (Foucault 1996 30).
} 
En el reverso de los dispositivos inmunitarios del nazismo -la normativización de la vida, el doble cierre del cuerpo y supresión anticipada del nacimiento- Esposito cree haber hallado algunas pistas que, a través de Spinoza, Nietzsche, Simondon y Canguilhem, pero también de Deleuze, lo conducen hacia un pensamiento afirmativo de la biopolítica - una política no sobre la vida, sino de la vida-, introduciéndose en los pliegues internos del léxico nazi para abrir desde allí, las fisuras que permitan invertir afirmativamente sus constricciones inmunitarias, proyectando no tanto una politización de la vida (imponer a la vida presupuestos categoriales que la definan y encierren) sino una vitalización de la política que, de partida, la desplace de su localización institucional ${ }^{16}$.

En un recorrido por aquellos pasajes no menos problemáticos de la experiencia nazi, Esposito nos advierte que la suspensión del orden jurídico durante el Tercer Reich (su carácter extralegal) no supuso la ausencia de una norma operando. Más bien, un concepto de la misma radicalmente novedoso pero no diferente de los anteriores, que si bien obedecía a los regímenes de excepción conceptualizados por Carl Schmitt,

No se quería obtener un orden sustraído de la norma sobre la base de continuas decisiones subjetivas, sino, por el contrario, de su devolución a un marco normativo de carácter objetivo, en cuanto originado en las necesidades vitales del pueblo alemán (Esposito 2011 293).

El trasfondo epistémico provoca un cortocircuito tanto con las corrientes iusnaturalistas como normativistas (porque, a decir verdad, el nazismo es la expresión paroxística de ambas), de modo que la juridización de la vida que despliega el nazismo es complementaria a su vez con la biologización del derecho: un derecho natural amparado en el estrato biológico inmanente. El criterio racial constituido por el rasgo biológico de la sangre, determinaba entonces el estatuto jurídico de las personas.

Desde este punto de vista, la "jurisprudencia" nazi no puede relacionarse con una radicalización subjetivista ni decisionista del derecho positivo, sino, a lo sumo, con un forma perversa de derecho natural, evidentemente a condición de no entender por "naturaleza" la ley revelada por la voluntad divina ni la originada en la razón humana, sino el estrato biológico donde se enraíza el ordenamiento nacional (Esposito 2011 293-294).

La función aquí desempeñada por el lenguaje jurídico es la de asegurar que ese contenido biológico inherente a la condición humana quedara inscrito en las cesuras constitutivas del derecho, siendo la naturaleza vital en tanto que superficie, el lugar de aplicación de una norma que presupone la facticidad de la vida y de

${ }^{16}$ Lo cual exige necesariamente una transformación del léxico político heredado por la modernidad. $\mathrm{Al}$ respecto, se puede revisar el trabajo de Roberto Esposito "Categorías de lo impolítico" (1996). 
una vida que se reconoce previamente en las divisiones de la norma, lo cual da como resultado la existencia de leyes biopolíticas (un bioderecho).

Sólo una vida ya "decidida" según determinado orden jurídico puede constituir el criterio natural de aplicación del derecho. Desde este ángulo, bien puede decirse que, a su modo, el nazismo creó una "norma de vida": no, por cierto, en el sentido de adecuar sus propias normas a las necesidades de la vida, sino en el de encerrar toda la extensión de la vida dentro de los límites de una norma destinada a volverla su opuesto. Al aplicarse directamente a la vida, el derecho nazi sometía a una norma de muerte que simultáneamente la absolutizaba y la destituía (Esposito 2011 294)

Ante ello, Esposito se pregunta cómo invertir la relación potencialmente destructiva que implicó la "norma de vida" del bioderecho nazi. Para que la norma pueda vitalizarse, tanto la vida como el derecho requieren ser pensados desde otros horizontes de sentido. En esos términos es que las nociones (más bien, intuiciones) de Spinoza sobre un vitalismo jurídico deben ser interpretadas en una perspectiva de la potencia y lo contingente, y no como una ley prescriptiva de origen divino o asentada en la razón humana, en la medida que lo natural de la vida es justamente su tendencia a sobrepasarse.

Según creo, la clave teórica de este pasaje no está en ninguna de las grandes filosofías jurídicas modernas: ni en el positivismo ni en el iusnaturalismo, ni en el normativismo ni en el decisionismo. Al menos no está en ninguna de aquellas a las que la modernidad llevó a término y simultáneamente a su disolución. Desde este punto de vista, no sólo Kelsen y Schmitt, sino incluso Hobbes y Kant, resultan inutilizables a los fines de un pensamiento afirmativo de la biopolítica: o bien son constitutivamente ajenos a su léxico, como Kant y Kelsen, o bien están contenidos en su pliegue negativo, como Hobbes y Schmitt. Un hilo que, en cambio, es posible, y tal vez necesario, volver a tejer está incluido en la filosofía de Spinoza, en la exacta medida en que permanece ajena, o paralela, respecto de las líneas dominantes de la tradición jurídica moderna (Esposito 2011 296).

Esposito considera que el gran impacto que la filosofía de Spinoza produce en el pensamiento moderno, desestabilizando sus sistemas conceptuales, es pasar de la lógica de la presuposición -respecto a la relación entre derecho y vida- a la de una inmanencia recíproca. Se trata de que tal presuposición resulta innecesaria en la medida que norma y vida son elementos consustanciales, copertenecientes a la misma dimensión vital. No puede la norma actuar sobre la vida porque coincide con ella, así como la vida no puede presuponer una norma jurídica porque es ella misma la norma en continuo movimiento.

Siguiendo este camino, Spinoza logra evitar el formalismo de la obligación moderna -en especial, hobbesiana-, sin caer en un sustancialismo biológico como el nazi: lo aleja de ambos el rechazo de ese paradigma soberano que, no obstante todas las diferencias, los conjuga en una idéntica actitud coercitiva. Cuando en una 
celebérrima proposición del Tratado político escribe que "cada cosa natural tiene, por naturaleza, tanto derecho cuanto poder posee para vivir y para actuar", también él está pensando en una "norma de vida", pero en un sentido que, antes que implicar la una a la otra, las une en un mismo movimiento, que considera a la vida normada desde siempre, y a la norma, como provista naturalmente de contenido vital. La norma ya no es, como en el trascendentalismo moderno, aquello que desde fuera asigna al sujeto sus derechos y deberes, permitiéndole lo que es lícito y vedándole lo que está prohibido, sino la forma esencial que cobra la vida en la expresión de su propio incontenible poder de existir" (Esposito $2011297-$ 298)

Es probable que uno de los motivos de la resistencia por parte de la filosofía del derecho a pensar la norma en plena coincidencia con la vida, o incluso a aludir directamente a un vitalismo jurídico, obedezca a los prejuicios antibiológicos intensificados tras la catástrofe totalitaria de la primera mitad del siglo XX. En ese sentido, y como considera Esposito, Simondon es uno de los investigadores que, en la tradición spinoziana, habría centrado su trabajo en el desarrollo de la vida individual y colectiva desde la noción de lo "transindividual", al igual como fue formulado por Spinoza, para quien los individuos no eran entidades estables y homogéneas, sino elementos que surgen de un proceso de sucesivas individuaciones, al que continuamente reproducen. Eso sucede no sólo porque, como teorizará más tarde Nietzsche, cada cuerpo individual es un compuesto de partes provenientes de otros individuos y en movimiento hacia ellos, sino, además, porque su potencia expansiva es proporcional a la intensidad y a la frecuencia de ese intercambio, de modo que, en el ápice de su desarrollo, se encontrará inserto en una relación cada vez más amplia y compleja con el ambiente, que sólo en muy reducida medida dejará subsistir su identidad originaria (Esposito 2011 300).

En la concepción spinoziana del derecho, la multiplicidad de los individuos es el criterio que determina la multiplicación exponencial de las normas. Es de este modo que las normas si ya no son externas sino intrínsecas al individuo (son el individuo en su dinamismo inestable), no sólo no puede existir una norma fundamental o un criterio normativo primigenio o último, sino que además la norma no puede mediar un conflicto del que forma parte.

Desechadas ya las formas de trascendentalismo jurídico y de sustancialismo biológico, lo que queda es pensar la norma en la estructura de la composición biológica de la vida, y sólo allí esa natural tendencia a imaginar normas absolutas e inmutables -como reconoce Esposito- puede ser mediada por el paso desde lo preindividual hacia lo transindividual que, en Simondon, inscribe la norma en esas formas variables que pertenecen al movimiento de la vida, siempre transitorias, 
nunca acabadas, haciendo de la vida "la fuente primaria de institución de las normas" (Esposito 2011 302)

Será George Canguilhem -maestro de Simondon- quien presente la versión más pregnante de un nuevo concepto de norma. Desde su reconocido compromiso militante, se dispone a pensar una salida a la "norma de vida" nazi que no esté, sin embargo, destinada a reinscribir los modelos jurídicos anteriores, instaurando la separación entre la vida y el concepto objetivista de la misma (cuya estirpe sería su contenido biológico), puesto que si la vida está entregada al constante desplazamiento, ningún concepto puede permitirse englobarla definitivamente.

De esto, se sigue la imposibilidad de separar la vida de su forma, a diferencia de lo que fue para el nazismo.

El instrumento conceptual empleado para tal fin es, precisamente, la categoría de norma. Considerada por la tradición jurídica -y también sociológica, antropológica, pedagógica- como parámetro, a la vez descriptivo y prescriptivo, para evaluar el comportamiento humano, Canguilhem la reconduce al significado de puro modo, o estado, del ser viviente. En este caso, no sólo la salud, sino también la enfermedad, constituye una norma que no se superpone a la vida, sino que expresa una situación específica de ella (Esposito 2011 304).

Para Canguilhem y su lógica normativa, lo anormal no se separa ni transgrede sino que pertenece al ámbito de la norma. Esto indica que si sólo la transgresión de una norma es lo que permite que la misma resulte cognoscible, como la salud que se eleva a la consciencia humana cuando se ha visto alterada, lo anormal es "existencialmente primero".

Debido a esta ubicación secundaria respecto de lo que la niega, la norma no puede anteponerse, o imponerse, a la vida, sino tan sólo derivarse de ella. Ya se torna evidente aquí la deconstrucción que -a partir del paradigma biológico, liberado a su vez de toda objetivación presupuesta- lleva a cabo Canguilhem en relación con la norma jurídica. Mientras esta, fijando un código de comportamiento anterior a su plasmación, debe necesariamente prever la posibilidad de desviación de la vida, y por ende la sanción correspondiente, la norma biológica coincide con la condición vital en que se manifiesta (Esposito 2011 305).

Si la norma es aquello en que la existencia biológica de un organismo lo hace coincidir consigo mismo, ya no puede pensarse la norma, en los términos aquí expuestos, desde el lenguaje jurídico sin que éste se vea sometido a una mutación radical de su léxico, y en ese sentido ya la vida no es bloqueada en un esquema rígido determinado por la norma, sino que la norma es expuesta a la apertura imprevisible de la vida.

Desde luego, no tiene sentido aquí contraponer el derecho a la vida, como el lenguaje a la composición biológica, porque la vida es el cruce de ambos vectores, 
la conexión entre naturaleza e historia. Los cuerpos vivientes son tanto órganos biológicos como entidades culturales, sin que esa existencia cultural esté determinada por una capa natural metalingüística, o que el lenguaje sea representativo de un contenido presocial desde donde éste se despliega. Lo distintivo en Canguilhem es, en definitiva, abrir paso a la perspectiva de una norma biológica afirmativa, respecto al carácter prohibitivo del orden jurídico en los términos inmunitarios del mismo.

Aquí, Canguilhem introduce el vector más innovador de su propuesta, justamente en el punto de enlace y de diferencia entre normalidad y normatividad. Derivados del latino norma, ambos términos se tensan en una definición que al mismo tiempo los superpone y los separa: plenamente normal no es quien está en correspondencia con un prototipo prefijado, sino el individuo que conserva intacto su propio poder normativo, esto es, la capacidad de crear continuamente nuevas normas (Esposito 2011 306)

Finalmente, Esposito desemboca su análisis en Deleuze y su último texto titulado "La inmanencia: una vida", donde podrían imbricarse los elementos antes expuestos que, desde Spinoza a Simondon y Canguilhem, hacen coincidir la vida con la norma, o hacen de la vida la norma de su propio devenir continuo y cambiante. En la noción de "campo trascendental" de Deleuze, "entendido no como algo que remite a un objeto ni a un sujeto, sino como el flujo, potenciador o debilitante, entre una sensación y otra" (Esposito 2011 307), se despliega un plano de inmanencia absoluta, es decir lo trascendental del bíos es inmanente a sí mismo, donde el motivo de la muerte aparece otra vez como un aspecto decisivo.

El paso del artículo determinado al indeterminado tiene la función de señalar la ruptura del rasgo metafísico que conecta la dimensión de la vida con la de la conciencia individual: hay una modalidad del bíos imposible de inscribir en los confines del sujeto consciente $y$, por tanto, no atribuible a la forma del individuo o a la persona. Deleuze la busca en la línea extrema en que la vida se encuentra, o choca, con la muerte (Esposito 2011 308).

En Deleuze (tomando un texto de Dickens y el personaje Riderhood en coma), la singularidad está siempre ubicada del lado de lo impersonal, por ello la muerte aparece entonces como el signo que proyecta esos instantes de suspensión (entre la vida y la muerte) en que se ha diseminado la figura del individuo consciente y sin embargo se conserva la singularidad de la vida.

Una vida así, el "así" de una vida -prosigue Deleuze-, no es "individuable", reconducible al individuo, porque es de por sí genérica, concerniente a un género, más también inconfundible, en cuanto única en su género, como la de un recién nacido, semejante a todos los demás pero distinto de cada uno de ellos por su tono de voz, por la intensidad de su sonrisa, el destello de una lágrima. Es constitutivamente impropia, y por ello común, como puede serlo la pura diferencia, la diferencia no definida por otra cosa más que su puro diferir (Esposito 2011 310). 
Lo impropio de la communitas, como resultado de la genealogía etimológica a la que Esposito somete el concepto de comunidad, permite situarnos otra vez en la idea de lo puro en Walter Benjamin. Que la communitas sustrae la identidad de los individuos, es un aspecto significativo para comprender la relación entre comunidad y muerte, o comunidad y violencia, que la filosofía moderna suscribiera como una relación que debe ser protegida de su potencial destrucción recíproca. Allí, sin embargo, estaría la clave comprensiva para aproximarnos a una biopolítica afirmativa, de acuerdo a la propuesta de Esposito:

Cuando Deleuze habla de una "suerte de beatitud" como de una condición más allá de la distinción entre el bien y el mal, porque antecede, o quizá sigue, al sujeto normativo que la realiza, alude él también a una "norma de vida" que, en vez de someter la vida a la trascendencia de la norma, haga de la norma el impulso inmanente de la vida. La referencia a lo impersonal, como única modalidad vital de lo singular, no es ajena a la superación de una semántica de la persona, representada, desde el origen de nuestra cultura, en su estatuto jurídico, al menos en la medida en que el derecho fue y sigue siendo funcional para la individualidad intangible de la persona. Deleuze invita a deshacer este nudo biojurídico entre vida y norma de una manera que, en vez de separarlas, reconozca la una en la otra, encuentre en la vida su norma inmanente y restituya a la norma el poder en devenir de la vida (Esposito 2011 312).

\section{Conclusiones}

Hemos visto que el revés sacrificial de la biopolítica no radica tanto en el deber más alto de la autoconservación de la vida como signo del biopoder sino en que la protección se realice de un modo aporético, de tipo homeopático, en que la producción de vida deviene emparentada con la generación de muerte. Si el derecho inmuniza la vida garantizando la absoluta disponibilidad de bienes conmutables en dinero- para que sean reivindicados por quienes legítimamente reclamen su posesión (destituyendo lo común), ello bloquea cualquier relación que no esté inspirada en el sentido de la pertenencia, pero además consolida la afirmación por la vía de la negación.

Este "derecho propio", que siempre es de alguien y remite a lo personal, (sea público o privado), que además se funda en la fuerza y se conserva a través de la misma, está destinado a salvaguardar la vida subordinándola a su decisión trascendente, como si se tratara de una norma absolutamente extrínseca, erguida en el proceso de despolitización creciente que acarrea la modernidad expresado en la esfera neutral de la técnica, que a fin de cuentas -como ha sido afirmado por 
Esposito- es el más invasivo de los mitos modernos, que encontrará en la crítica a la razón emprendida por Adorno y Horkheimer un contrapunto significativo ${ }^{17}$. En lo impersonal e impropio, ya sea del "campo trascendental" y la inmanencia de Deleuze como de la communitas en Esposito, podría entonces situarse la idea de lo puro de Walter Benjamin. Como ha sido advertido, al tratarse de una concepción relacional y no sustancial, su distinción -en el caso de Para una crítica de la violenciaes respecto al derecho, o a la violencia mítico-jurídica, y a cuya puricidad Schmitt reconducía al contexto jurídico del Estado de excepción. En cambio, lo puro en Benjamin podría considerarse como la forma de la relación que, signada por lo impersonal e impropio $\mathrm{y}$, si se quiere, por la "des-individualización", es el único modo de existencia de la singularidad.

Si la idea de un medio sin fin conlleva una crítica de la racionalidad instrumental ¿qué otro ámbito que no sea una relación podría carecer de un fin y, en vez de eso, hacer de su inmanencia el impulso vital que la empuja a trascender? De este modo, la relación no es la instancia donde los individuos prefigurados se conectan, sino el acontecimiento que los constituye y al mismo tiempo los rebasa, donde la relación deviene vaciamiento.

Si aquello puro es la pura relación (el ser-en-el-mundo, el Dasein de Heidegger), ésta deja de ser instrumento de fines individuales o colectivos, y ya no es asimilable a una filosofía política, porque no reconoce origen por restituir ni destino por alcanzar. Es lo inapropiable de la communitas en la medida que su ley, la del munus, hace del cum -es decir, el entre- el precipicio hacia el vacío del lugar común, que es la génesis de toda existencia: relacionados por la ausencia de pertenencia, de modo que la comunidad "no es un 'ente', sino precisamente un noente, una nada que precede y corta todo sujeto sustrayéndolo de la identidad consigo mismo, confinándolo a una alteridad irreductible" (Esposito 2009 48).

Desde este punto de vista, cualquier esfuerzo por alcanzar un fin no es menos inútil que el de reapropiarse de un origen perdido en determinado momento. La comunidad no está ni antes ni después de la sociedad. No es lo que la sociedad suprimió, ni lo que ella debe proponerse como objetivo. Así como no es resultado de un pacto, de una voluntad o de una simple exigencia que los individuos comparten. Pero tampoco es el lugar arcaico del que ellos provienen y que abandonaron. $\mathrm{Y}$ ello por el simple dato fáctico de que no existen individuos fuera de su ser-en-un-mundo-común (Esposito 2012 156).

17 "Pero los mitos que caen víctimas de la Ilustración eran ya producto de ésta. En el cálculo científico del acontecer queda anulada la explicación que el pensamiento había dado de él en los mitos. El mito quería narrar, nombrar, contar el origen: y con ello, por tanto, representar, fijar, explicar. Esta tendencia se vio reforzada con el registro y la recopilación de los mitos. Pronto se convirtieron de narración en doctrina" (1994 63). 
Pero lejos de negar por anticipado toda posibilidad de inmunización, toda forma de propiedad o subjetivismo, otra vez se trata de invertir sus presupuestos para hallar modalidades afirmativas de la identificación, como una inmunidad (inmunidad tolerante al munus, dirá Esposito) que proteja de cualquier sustancialismo biológico o esencialismo metafísico, aquello que remite a la figura del sujeto la cual, según la definición de Foucault, encuentra sentido en el sometimiento, a sí mismo o a otros.

De ahí que la semántica del derecho moderno, orientada hacia la apropiación de la Cosa, resulte incompatible con esa nada de la comunidad, su apertura irrealizable que es el mundo común, la relación, ser-en-común, desde donde es posible proyectar no sólo una biopolítica afirmativa sino que, junto con ella -recusando todo carácter procedimental- una "democracia pura", democracia de los comunes ("democracia por venir", como en Derrida), en un sentido similar al que Agamben alude en esta sentencia elucidante respecto al problema que aquí hemos examinado:

Un día la humanidad jugará con el derecho, como los niños juegan con los objetos en desuso no para restituirles su uso canónico sino para librarlos de él definitivamente. Lo que se encuentra después del derecho no es un valor de uso más propio y original, anterior al derecho, sino un uso nuevo que nace solamente después de él. Inclusive el uso, que se ha contaminado con el derecho, debe ser liberado de su propio valor. Esta liberación es deber del estudio o del juego. Y este juego estudioso es el paso que permite acceder a esa justicia, que un fragmento póstumo de Benjamin define como un estado del mundo en el cual éste aparece como un bien absolutamente inapropiable e imposible de subsumir en un orden jurídico (Agamben 2005 121).

Un derecho que se intersecta con la vida hasta confundirse con la misma (que ya no es propio de alguien, sino impersonal de todos), no es ya nunca más "derecho" sino más bien una vida, que es inexorablemente una forma de vida: impulso inquebrantable de la comunidad que tiende a sobrepasarse, a vivir en el límite, a ser potencia y ser en potencia, a ir siempre más allá de sí misma.

\section{Bibliografía}

Adorno, Theodor y Horkheimer, Max. Dialéctica de la Ilustración: Fragmentos filosóficos. Madrid, España: Editorial Trotta, 1994.

Agamben, Giorgio. Estado de excepción. Homo Sacer II, I. Buenos Aires, Argentina: Adriana Hidalgo editora, 2005.

Esposito, Roberto. Immunitas: Protección y negación de la vida. Buenos Aires, Argentina: Amorrortu. 2005. 
Esposito, Roberto. Comunidad, inmunidad y biopolítica. Barcelona, España: Herder Editorial, 2009.

Esposito, Roberto. Bíos: Biopolítica y Filosofía. Buenos Aires, Argentina: Amorrortu, 2011.

Esposito, Roberto. Communitas. Origen y destino de la comunidad. Buenos Aires, Argentina: Amorrortu, 2012.

Esposito, Roberto. El dispositivo de la persona. Buenos Aires, Argentina: Amorrortu, 2011.

Foucault, Michel. La verdad y las formas jurídicas. Barcelona, España: Editorial Gedisea, 1996.

Foucault, Michel. Genealogía del racismo. La Plata, Argentina: Editorial Altamira, 1996.

Foucault, Michel. Las redes del poder. Buenos Aires, Argentina: Prometeo Libros, 2014.

Marx, Karl. Sobre la cuestión judía. Barcelona, España: Anthropos Editorial, 2009.

Spinoza, Baruch. Tratado político. Madrid, España: Alianza Editorial, 2013.

Weil, Simone. Echar raíces. Madrid, España: Editorial Trotta, 1996. 